\title{
The relationships between field dependent/independent cognitive styles and information \& communication technologies based programs in gifted education
}

\author{
Hakan Üstünel ${ }^{1}$ \\ Erdem Uçar ${ }^{2}$ \\ Turhan Civelek ${ }^{3}$ \\ İlhan Umut ${ }^{2}$
}

\begin{abstract}
The research aims to investigate gifted students' FD/FI cognitive styles and factors affecting them like preferring to take Information \& Communication Technologies-based courses at gifted children's school. The study was carried out on two groups. First group consisted of 52 students identified as gifted who are attending 6th and 7th grades at the Istanbul Science \& Art Center in Istanbul, Turkey, the second group consisted of 38 students who are not identified as gifted and totally the study consists of 90 students. In order to collect data pertaining to this research, Group Embedded Figures Test (GEFT) was used to measure Field Dependence/Field Independence, $(\mathrm{FD} / \mathrm{FI})$. According to the findings of the research, it has been observed that there is a significant difference between favored gifted students' cognitive style scores and other students' who are not identified as gifted. There is also a significant difference between in favor of Information\& Communication Technologies (ICT) based course taking gifted students' cognitive style scores and other gifted students who are not taking ICT-based courses in Science and Art Center. In contrast to these, there is not a significant differences were found on cognitive styles in terms of gender and grade variants in both groups.
\end{abstract}

Keywords: FD/FI cognitive styles, gifted education, human computer interaction, special education

\section{Introduction}

The notion about teaching and learning entitle to the opinions held by teachers about their preferred ways of teaching and learning. This encloses the meaning of teaching and learning and the roles of teachers and pupils (Chan \& Elliot, 2004). Teaching and learning processes are influenced by different cognitive variables. Educational coursework often includes emphasis on learning styles,

\footnotetext{
1 PhD, Istanbul Science \& Art Center, hakanustunel@hotmail.com

2 Assist. Prof. Dr., Trakya University, Computer Engineering Department

${ }^{3}$ Assist. Prof. Dr., Kurklareli University, Software Engineering Department
} 
Üstünel , H., Uçar, E., Civelek, T. \& Umut, İ. (2015). The relationships between field dependent/independent cognitive styles and information \& communication technologies based programs in gifted education. International Journal of Human Sciences, 12(2), 266-277. doi: 10.14687/ijhs.v12i2.3257

cognitive styles, personality traits, motivational differences, or intelligences, and their possible significance during instruction (Rittschof, 2010).Recent studies argued that in today's world environment in which this process occurs primarily at one of the information is transmitted to students by teachers in most education institutions. Readiness, prior learning, teaching styles, cognitive styles, materials used, and many other factors can also influence which education process. Gifted children; intellectual, creative, artistic, or leadership capacity in areas such as highperformance fully develop their capacity for showing or in specific academic fields, which did not achieve in school events and activities the child is in need of (Kirk \& Gallogher, 1989).

If gifted students receive training which has been designed according to individual needs they may develop a sense of competence and positive self-perception. Otherwise, the unsuccessful can take place in the highest risk group for them. They receive proper training by working more efficiently and effectively to improve high-level problem-solving skills. After this, students synthesize information assimilated by combining and this can bring numerous solutions. There are several definitions of the term "cognitive style" in the literature. According to Messick (1984), cognitive style deals with the manner in which people prefer to make sense out of their world by collecting, analyzing, evaluating, and interpreting data.. A detailed description of the relevant cognitive styles and approaches are tabulated by Daniels (1996). With respect to Witkin \& Goodenough (1981) cognitive style is; the individual's knowledge receiving, processing, organizing, memory retention and in the process of using the preferred methods.

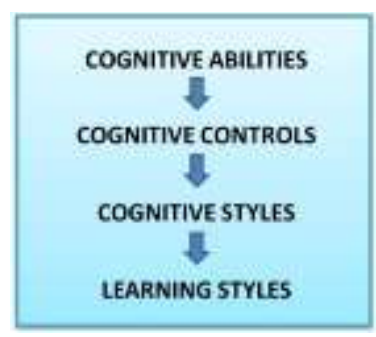

Figure1.The relational transition of cognitive processes (Jonassen \& Grabowski, 1993).

The relational transition of cognitive processes is from general to specific features, shown in figure 1. Assorted forms of cognitive styles have been introduced and dissimilar instruments have been improved to determine them, Witkin et al.'s (1971) Group Embedded Figures Test (GEFT) has been applied mostly. Field dependence/ independence is a relatively well-established construct, and has been the subject of much research for over 30 years.

Many experimental studies have shown the impact of FD/FI on learning process and academic achievement. Inquiries have specified a number of relationships between FD/FI cognitive style and learning including the ability to learn from social environments, types of educational consolidation needed to improve learning and amount of structure preferred in an educational environment. Numerical estimation can provide information about an individual's general understanding of number concepts, relationships, and strategies, and can reveal cognitive development in mathematical domains. Certain individuals possess highly intuitive implicit processing abilities $(\mathrm{Xu}$, et al., 2011).

Additionally some investigations reveals that both developmental and cultural differences affect on FD/FI cognitive style scores (Thomson et al.,2014). The results of a research study on adaptive educational system based on cognitive styles indicated that the subject's performance test indicated that subject's performance was increased after the instruction. Furthermore, FI subjects had better 
Üstünel , H., Uçar, E., Civelek, T. \& Umut, İ. (2015). The relationships between field dependent/independent cognitive styles and information \& communication technologies based programs in gifted education. International Journal of Human Sciences, 12(2), 266-277. doi: 10.14687/ijhs.v12i2.3257

results than FD subjects (Triantafillou et al., 2003). In addition to this, as a result of his research Bahar (2003) indicates that FI students appeared to be superior to FD students. In some degree, FI individuals are more adept at structuring and thinking analytically in correlation to their FD provisions. Comparatively, FD individuals evolve more in situations where learning is structured and analyzed for them (Ford, 2000).

Daniels (1996) summarizes the general tendencies of field dependent and independent learners as follows:

\section{Field-dependents:}

- Rely on the surrounding perceptual field.

- Have difficulty attending to, extracting, and using non salient cues.

- Have difficulty providing structure to ambiguous information.

- Have difficulty restructuring new information and forging links with prior knowledge.

- Have difficulty retrieving information from long-term memory.

\section{Conversely, field-independents:}

- Perceive objects as separate from the field.

- Can dissembled relevant items from non-relevant items within the field.

- Provide structure when it is not inherent in the presented information.

- Reorganize information to provide a context for prior knowledge.

- Tend to be more efficient at retrieving items from memory (p. 38)

\section{The Research Problem}

There is not any research conducted on gifted students' FD $\backslash$ FI cognitive styles related ICT-based education programs at gifted schools in the literature. In this respect the research is important for the literature. This research study aims to investigate the following research questions;

- Is there any significant difference between gifted students' FD FI cognitive styles for taking ICT-based course in terms of, gender and grade?

- Is there any significant difference between giffed students' and other students' FD FI cognitive styles in terms giftedness, gender and grade?

\section{Methodology}

\section{Sample of the study}

The study was carried out on two groups. The First group consisted of 52 students who are identified as gifted as gifted who are attending 6th and 7th grades at the Istanbul Science\&Art Center in Istanbul, Turkey. In addition to group 1 the study includes another group of students who are not identified as gifted students and these students form group 2 . The total number of the participants of the study is 90 student participants. 
Üstünel , H., Uçar, E., Civelek, T. \& Umut, İ. (2015). The relationships between field dependent/independent cognitive styles and information \& communication technologies based programs in gifted education. International Journal of Human Sciences, 12(2), 266-277. doi: 10.14687/ijhs.v12i2.3257

Table 1. Distribution of Sample of Research Groups

\begin{tabular}{lcccc}
\hline \multicolumn{2}{c}{ Research Groups } & Girl & Boy & Total \\
\hline Group 1 & Gifted & 18 & 34 & 52 \\
\hline \multirow{3}{*}{ Group 2 } & Gifted & 18 & 34 & 52 \\
& Unidentified & 15 & 23 & 38 \\
& Total & 33 & 57 & $90^{*}$ \\
\hline * Group 2 total & & & &
\end{tabular}

WISC-R (Wechsler Intelligence Scale for Children-Revised) scores of all the gifted students who participated in the research are over 130. In the statistical evaluation of the results the research, the hypotheses are established for each group separately.

\section{Assessment Instruments}

In this research to examine students' level of field dependency, Group Embedded Figures Test (Field Dependent/Field Independent Test - FD/FI Test) was used. the test used in this research was designed and adapted by El- Banna (1987) from Witkin's (1977) underlying tests instrument. Bahar (2003) found the coefficient value of FD/FI test. The reliability was found to be 0.812 that indicates high reliability of the test.

It includes 20 complicated figures. Students were required to recognize and identify a hidden basic shape in each of the set of complex figures and outline it on the lines of the complicated figure. The more sample figures correctly found, the better the student is at this process of separation of a figure from a confusing background, is said to be FI. There is a segment between these two segment, are classified as Field intermediate (FINT).

A procedure was used to create the three categories, that is FD, FINT and FI. The procedure is as follows:

- More than one-quarter of a Standard deviation (SD) above the mean score were classified as FI (Mean+SD*0,25).

- Under one-quarter of a SD below the mean score were classified as FD (Mean-SD*0,25).

- Between a score of plus or minus one quarter of a SD around the mean were considered as FINT $($ FD $<$ FINT $<$ FI).

\section{Educational Practices at Science \& Art Center}

Students admitted to the Science \& Art Center when they when they are continuing studying at 4th grade in primary school. There is an exam constructed for the voluntary students, a two stage exam which consists of 2 different tests. At the first stage a kind of performance test named TKT (Teaching Knowledge Test) is performed by the students. TKT is used to determine a child's mental performance and is an aptitude test which consists of sub-tests (Language, shape-space, reasoning, discrimination and to calculate).

At the second stage WISC-R test is applied to the students who are successful at TKT. The student, who has score above 130, is accepted to attend Science \& Art Center by continuing 5th grade his/her secondary school.

In the first year at the Science \& Art Center gifted students are taken to Orientation and Noticing Individual Abilities (NIA) schedules respectively. By going through the NIA program, students get 21 lectures superficially. After finishing the NIA Schedule, students have an opportunity to choose 
Üstünel, H., Uçar, E., Civelek, T. \& Umut, İ. (2015). The relationships between field dependent/independent cognitive styles and information \& communication technologies based programs in gifted education. International Journal of Human Sciences, 12(2), 266-277. doi: 10.14687/ijhs.v12i2.3257

only 3 lectures from 21 courses for following year, 6th grade. The course choosing process is important for having progress, choosing and focusing incorrect courses will be waste of time for students.

Each course is constructed step by step which is going from easy to difficult and from general to specific levels. If a student does not want to continue to a course is chosen by her/him any more, $\mathrm{s} /$ he can choose new one instead of the previous one. If anyone wants to be successful on a course $\mathrm{s} /$ he has to continue to the course for years to be experienced and skillful.

At Istanbul Science \& Art Center, information and communication technologies (ICT) based on the applicants' subjects are listed below;

- Web programming SQL. NET, ASP, PHP,HTML5

- Graphic Programming \& Design (OpenGL, Maya, Sketch Up, SolidWorks)

- Visual $\mathrm{C}++, \mathrm{C \#}, \mathrm{C}++$ console applications

- Digital electronics

- Basic electronics

- Computer mathematics (logic, number systems, etc.).

- PIC programming

- PLC programming

- Basic and intermediate robotics

The mentioned subjects are presented at the 4 laboratories by 5 ICT teachers $\backslash$ mentors. In order to give students have an opportunity to develop their projects, the centre provides such ICT-based courses which are designed as step by step the progression. In the first two years, students make their decision optionally on that $\mathrm{s} / \mathrm{he}$ is willing to continue to discover the field or not. In later years, students change fields at a declining rate.

Moreover, it is significant for this research, isthere any difference between not taking the ICT courses gifted students' FD/FI cognitive styles and taking students'.

\section{Data collection procedure and Analysis}

The data was collected during the fall term of 2013-2014. At the end of the fall semester, participants were asked to participate in this study on a volunteer base. The research data was analysed statistically through SPSS v20.0 software program. Data was analysed with respect to 'cognitive style scores', 'FD/FI cognitive styles', 'giftedness', 'taking ICT-based course in gifted school', 'gender' and 'grade' variants. Findings were summarized in Tables 2, 3, 4, 5, 6 and 7.

\section{Kolmogorov-Smirnov Test Results of Group 1 Sample for Normality of the Data}

The research data was analysed in terms of normality and according to the results of this test parametric or nonparametric tests were selected. Significant values $(p)$ of variants in terms of cognitive styles scores are listed below respectively;

- Gender - girls and boys $(0.135 ; 0.276)$

- Giftedness - yes and Unidentified $(0.067 ; 0.200)$

- Grade $6^{\text {th }}$ and $7^{\text {th }}(0.087 ; 0.200)$ 
Üstünel , H., Uçar, E., Civelek, T. \& Umut, İ. (2015). The relationships between field dependent/independent cognitive styles and information \& communication technologies based programs in gifted education. International Journal of Human Sciences, 12(2), 266-277. doi: 10.14687/ijhs.v12i2.3257

The data were normally distributed. Therefore t-test was selected.

Significant values $(p)$ of variants in terms of cognitive styles are both below $0.05(0.00)$. The data were not normally distributed. Therefore mann-whitney-U test was selected.

Kolmogorov-Smirnov Test Results of Group 2 Sample for Normality of the Data

The research data was analysed in terms of normality and according to the results of this test parametric or nonparametric tests were selected. Significant values $(p)$ of variants in terms of cognitive styles scores are listed below respectively;

- Gender - girls and boys $(0.158 ; 0.276)$

- ICT-Based Course Student - yes and no $(0.200 ; 0.110)$

- Grade $6^{\text {th }}$ and $7^{\text {th }}(0.200 ; 0.200)$

The data were normally distributed. Therefore t-test was selected.

Significant values $(p)$ of variants in terms of cognitive styles are both below $0.05(0.00)$. The data were not normally distributed. Therefore mann-whitney-U test was selected.

For testing the significance between means, t-test and Mann-Whitney- $U$ test analysis were used. The mean of scores provided by both two groups, standard deviations, standard errors, t-u-z values and degrees of freedom were calculated.

\section{FINDINGS}

in this section findings obtained by the use of statistical analysis were shown with the help of the tables to evaluate the hypotheses related to cognitive styles. Each hypothesis was analyzed separately.

In the tables below for testing hypotheses, t-Test and Mann-Whitney-U Test statistics of all applications was calculated to determining whether there is a statistically significant difference according to the results of research subjects. Besides, it was checked for whether the confidence interval values of the data collected from study groups was overlapping on the numerical axis or not.

\section{Variation of Cognitive Style Scores for Sample of Group 1}

In the table below for testing hypotheses, $t$-Test statistics of all applications was calculated for determining whether there is a statistically significant difference according to the results of research subjects.

Gender $\mathrm{H}_{0}$ : There is no significant difference of gifted students' cognitive style scores in terms of gender variant.

Taking ICT-Based course $\mathrm{H}_{0}$ : There is no significant difference of gifted students' cognitive style scores in terms of taking ICT-Based course variant.

Grade $\mathrm{H}_{0}$ : There is no significant difference of gifted students' cognitive style scores in terms of grade variant $\left(6^{\text {th }}\right.$ and $7^{\text {th }}$ grades $)$. 
Üstünel, H., Uçar, E., Civelek, T. \& Umut, İ. (2015). The relationships between field dependent/independent cognitive styles and information \& communication technologies based programs in gifted education. International Journal of Human Sciences, 12(2), 266-277. doi: 10.14687/ijhs.v12i2.3257

Table 2. T-Test Results Comparing Gifted Students' Cognitive Styles Scores in Terms of Gender-Taking ICT-Based Course-Grade Variants

\begin{tabular}{|c|c|c|c|c|c|c|c|c|}
\hline Factors & Groups & $n$ & $M$ & $S D$ & $S E$ & $t$ & $d f$ & $p$ \\
\hline \multirow{2}{*}{ Gender } & Girl & 18 & 8,17 & 2,895 & 0,682 & \multirow{2}{*}{$-1,527$} & \multirow{2}{*}{50} & \multirow{2}{*}{0,133} \\
\hline & Boy & 34 & 9,53 & 3,145 & 0,539 & & & \\
\hline \multirow{2}{*}{ ICT-Based Course Student } & No & 22 & 7,41 & 2,84 & 0,605 & \multirow{2}{*}{$-3,658$} & \multirow{2}{*}{50} & \multirow{2}{*}{0,001} \\
\hline & Yes & 30 & 10,27 & 2,741 & 0,5 & & & \\
\hline \multirow{2}{*}{ Grade } & $6^{t h}$ & 30 & 9,57 & 3,036 & 0,554 & \multirow{2}{*}{1,394} & \multirow{2}{*}{50} & \multirow{2}{*}{0,169} \\
\hline & $7^{\text {th }}$ & 22 & 8,36 & 3,125 & 0,666 & & & \\
\hline
\end{tabular}

The scores of gifted students on ICT based course taking indicate these descriptive statistics, standard deviations for both groups were found as 2,741 and 2,840, means were found as 10,27 and 7,41 and standard errors were found as 0,500 and 0,605 respectively.

Since t-statistic value was bigger than critical value estimated for 95\% confidence interval, a significant difference was found in favor of ICT-Based course taking students' cognitive styles scores $[\mathrm{t}(50)=-3,658, \mathrm{p}<0,05)]$.

As t-statistic value was smaller than critical value estimated for $95 \%$ confidence interval, there is no significant differences found of cognitive style scores of gifted students on grade and gender variants ([p] 0,169>0,05 and [p] 0,133>0,05).

Table 3. Grade and Gender variants Distribution in Terms of Cognitive Styles

\begin{tabular}{|c|c|c|c|c|c|c|c|}
\hline \multirow{2}{*}{ Factors } & \multirow{2}{*}{ Groups } & \multicolumn{2}{|c|}{ Grade } & \multirow{2}{*}{ Total } & \multicolumn{2}{|c|}{ Gender } & \multirow{2}{*}{ Total } \\
\hline & & $\overline{6}^{\text {th }}$ & $7^{\text {th }}$ & & Girl & Boy & \\
\hline \multirow{3}{*}{ Field Dependent(FD) } & Not ICT-Based & 5 & 8 & 13 & 8 & 5 & 13 \\
\hline & ICT-Based & 5 & 3 & 8 & 1 & 7 & 8 \\
\hline & Total & 10 & 11 & 21 & 9 & 12 & 21 \\
\hline \multirow{3}{*}{ FINT } & Not ICT-Based & 3 & 3 & 6 & 3 & 3 & 6 \\
\hline & ICT-Based & 6 & 3 & 9 & 1 & 8 & 9 \\
\hline & Total & 9 & 6 & 15 & 4 & 11 & 15 \\
\hline \multirow{3}{*}{ Field Independent(FI) } & Not ICT-Based & 1 & 2 & 3 & 2 & 1 & 3 \\
\hline & ICT-Based & 10 & 3 & 13 & 3 & 10 & 13 \\
\hline & Total & 11 & 5 & 16 & 5 & 11 & 16 \\
\hline \multirow{3}{*}{ Total } & Not ICT-Based & 9 & 13 & 22 & 13 & 9 & 22 \\
\hline & ICT-Based & 21 & 9 & 30 & 5 & 25 & 30 \\
\hline & Total & 30 & 22 & 52 & 18 & 34 & 52 \\
\hline
\end{tabular}

\section{Variation of Cognitive Style (FD-FINT -FI) for Sample of Group 1}

In the table below for testing hypotheses, Mann-Whitney-U Test statistics of all applications was calculated for determining whether there is a statistically significant difference according to research subjects. 
Üstünel, H., Uçar, E., Civelek, T. \& Umut, İ. (2015). The relationships between field dependent/independent cognitive styles and information \& communication technologies based programs in gifted education. International Journal of Human Sciences, 12(2), 266-277. doi: 10.14687/ijhs.v12i2.3257

Gender $\mathrm{H}_{0}$ : There is no significant difference of gifted students' cognitive styles (FD- FINT FI) in terms of gender variant.

Taking ICT-Based course $\mathrm{H}_{0}$ : There is no significant difference of gifted students' cognitive styles (FD- FINT -FI) in terms of taking ICT-Based course variant.

Grade $\mathrm{H}_{0}$ : There is no significant difference of gifted students' cognitive styles (FD- FINT FI) in terms of grade variant $\left(6^{\text {th }}\right.$ and $7^{\text {th }}$ grades $)$.

Table 4.Mann-Whitney-U Test Results Comparing Gifted Students' Cognitive Styles (FD(0)- FINT (1)$\mathrm{FI}(2))$ in Terms of Gender- Taking ICT-Based Course -Grade Variants

\begin{tabular}{lcccccc}
\hline Factors & Groups & $n$ & $M$ & $U$ & $z$ & $p$ \\
\hline \multirow{2}{*}{ Gender } & Girl & 33 & 24,31 & 266,5 & $-0,809$ & 0,418 \\
\multirow{2}{*}{ ICT-Based } & Course & 57 & 27,66 & & & \\
Student & Not ICT-Based & 38 & 20,48 & & & \\
& ICT-Based & 52 & 30,92 & 197,5 & $-2,614$ & 0,009 \\
Grade & $6^{\text {th }}$ & 50 & 28,68 & & & \\
& $7^{\text {th }}$ & 40 & 23,52 & 264,5 & $-1,292$ & 0,196 \\
\hline
\end{tabular}

Since Mann-Whitney-U statistic value was bigger than critical value estimated for $95 \%$ confidence interval, a significant difference was found in favour of ICT-Based course taking gifted students' cognitive styles $(\mathrm{U}=197,500 ; \mathrm{z}=-2,614 ; \mathrm{p}<0,05)$. ICT-Based course taking gifted students' $(\mathrm{M}=30,92)$ cognitive styles more Field Independent(FI) property show than not ICT-Based course taking gifted students'(M=20,48).

As Mann-Whitney-U statistic value was smaller than critical value estimated for $95 \%$ confidence interval, there is no significant differences found of cognitive style of gifted students on gender and grade variants $([\mathrm{p}] 0,196>0,05$ and $[\mathrm{p}] 0,418>0,05)$.

\section{Variation of Cognitive Style Scores for Sample of Group 2}

In the table below for testing hypotheses, $t$ - Test statistics of all applications was calculated for determining whether there is a statistically significant difference according to research subjects.

Gender $\mathrm{H}_{0}$ : There is no significant difference between gifted students and not identified as gifted students' cognitive style scores in terms of gender variant.

Taking ICT-Based course $\mathrm{H}_{0}$ : There is no significant difference of cognitive style scores in terms of giftedness variant.

Grade $\mathrm{H}_{0}$ : There is no significant difference between gifted students and not identified as gifted students cognitive style scores in terms of grade variant $\left(6^{\text {th }}\right.$ and $7^{\text {th }}$ grades $)$. 
Üstünel, H., Uçar, E., Civelek, T. \& Umut, İ. (2015). The relationships between field dependent/independent cognitive styles and information \& communication technologies based programs in gifted education. International Journal of Human Sciences, 12(2), 266-277. doi: 10.14687/ijhs.v12i2.3257

Table 5.T-Test Results Comparing Cognitive Styles Scores in Terms of Gender-Giftedness-Grade Variants

\begin{tabular}{|c|c|c|c|c|c|c|c|c|}
\hline Factors & Groups & $M$ & $n$ & $S D$ & $S E$ & $t$ & $d f$ & $p$ \\
\hline \multirow{2}{*}{ Gender } & Girl & 6,76 & 33 & 3,354 & 0,584 & \multirow{2}{*}{$-0,937$} & \multirow{2}{*}{88} & \multirow{2}{*}{0,351} \\
\hline & Boy & 7,56 & 57 & 4,213 & 0,558 & & & \\
\hline \multirow{2}{*}{ Giftedness } & Unidentified & 4,82 & 38 & 3,608 & 0,585 & \multirow{2}{*}{$-5,979$} & \multirow{2}{*}{88} & \multirow{2}{*}{0.000} \\
\hline & Gifted & 9,06 & 52 & 3,102 & 0,43 & & & \\
\hline \multirow{2}{*}{ Grade } & $6^{\text {th }}$ & 7,2 & 50 & 4,468 & 0,632 & \multirow{2}{*}{$-0,186$} & \multirow{2}{*}{88} & \multirow{2}{*}{0,853} \\
\hline & $7^{\text {th }}$ & 7,35 & 40 & 3,159 & 0,499 & & & \\
\hline
\end{tabular}

In terms of cognitive style scores distribution of students on being gifted or not identified as gifted, standard deviations for both groups were found as 3,102 and 3,608, means were found as 9,06 and 4,82 and standard errors were found as 0,430 and 0,585 respectively.

Since t-statistic value was bigger than critical value estimated for $95 \%$ confidence interval, a significant difference was found in favor of gifted students' cognitive styles scores $[\mathrm{t}(88)=-$ $5,979, \mathrm{p}<0,05)]$.

As t-statistic value was smaller than critical value estimated for $95 \%$ confidence interval, there is no significant differences found of cognitive style scores on grade and gender variants $([\mathrm{p}] 0,351>0,05$ and $[\mathrm{p}] 0,853>0,05)$.

Table 6. Grade and Gender variants Distribution in Terms of Cognitive Styles

\begin{tabular}{|c|c|c|c|c|c|c|c|}
\hline \multirow{2}{*}{ Factors } & \multirow{2}{*}{ Groups } & \multicolumn{2}{|c|}{ Grade } & \multirow{2}{*}{ Total } & \multicolumn{2}{|c|}{ Gender } & \multirow{2}{*}{ Total } \\
\hline & & $6^{\text {th }}$ & $7^{\text {th }}$ & & Girl & Boy & \\
\hline \multirow{3}{*}{ Field Dependent(FD) } & Not ICT-Based & 15 & 10 & 25 & 10 & 15 & 25 \\
\hline & ICT-Based & 4 & 3 & 7 & 3 & 4 & 7 \\
\hline & Total & 19 & 13 & 32 & 13 & 19 & 32 \\
\hline \multirow{3}{*}{ FINT } & Not ICT-Based & 2 & 6 & 8 & 3 & 5 & 8 \\
\hline & ICT-Based & 10 & 13 & 23 & 8 & 15 & 23 \\
\hline & Total & 12 & 19 & 31 & 11 & 20 & 31 \\
\hline \multirow{3}{*}{ Field Independent(FI) } & Not ICT-Based & 3 & 2 & 5 & 2 & 3 & 5 \\
\hline & ICT-Based & 16 & 6 & 22 & 7 & 15 & 22 \\
\hline & Total & 19 & 8 & 27 & 9 & 18 & 27 \\
\hline \multirow{3}{*}{ Total } & Not ICT-Based & 20 & 18 & 38 & 15 & 23 & 38 \\
\hline & ICT-Based & 30 & 22 & 52 & 18 & 34 & 52 \\
\hline & Total & 50 & 40 & 90 & 33 & 57 & 90 \\
\hline
\end{tabular}

\section{Variation of Cognitive Style (FD- FINT -FI) for Sample of Group 2}

In the table below for testing hypotheses, Mann-Whitney-U Test statistics of all applications was calculated for determining whether there is a statistically significant difference according to research subjects.

Gender $\mathrm{H}_{0}$ : There is no significant difference between gifted students and not identified as gifted students cognitive styles (FD- FINT -FI) in terms of gender variant. 
Üstünel, H., Uçar, E., Civelek, T. \& Umut, İ. (2015). The relationships between field dependent/independent cognitive styles and information \& communication technologies based programs in gifted education. International Journal of Human Sciences, 12(2), 266-277. doi: 10.14687/ijhs.v12i2.3257

Taking ICT-Based course $\mathrm{H}_{0}$ : There is no significant difference of cognitive styles (FD-

FINT-FI) in terms of giftedness variant.

Grade $\mathrm{H}_{0}$ : There is no significant difference between gifted students and not identified as gifted students cognitive styles (FD- FINT -FI) in terms of grade variant ( $6^{\text {th }}$ and $7^{\text {th }}$ grades).

Table 7.Mann-Whitney-U Test Results Comparing Cognitive Styles (FD(0)- FINT (1)-FI(2)) in Terms of Gender- Taking ICT-Based Course -Grade Variants

\begin{tabular}{lcccccc}
\hline Factors & Groups & $n$ & $M$ & $U$ & z & $p$ \\
\hline \multirow{2}{*}{ Gender } & Girl & 33 & 43,5 & 874,5 & $-0,587$ & 0,557 \\
& Boy & 57 & 46,66 & & & \\
Giftedness & Unidentified & 38 & 31,09 & & & \\
& Gifted & 52 & 56,03 & 440,5 & $-4,748$ & 0,00 \\
Grade & $6^{\text {th }}$ & 50 & 47,05 & & & \\
& $7^{\text {th }}$ & 40 & 43,56 & 922,5 & $-0,668$ & 0,504 \\
\hline
\end{tabular}

Since Mann-Whitney-U statistic value was bigger than critical value estimated for $95 \%$ confidence interval, a significant difference was found in favor of gifted students' cognitive styles $(\mathrm{U}=440,500 ; \mathrm{z}=-4,748 ; \mathrm{p}<0,05)$.

Gifted students' $(M=56,03)$ cognitive styles more Field Independent(FI) property show than not identified as gifted students'(M=31,09).

As Mann-Whitney-U statistic value was smaller than critical value estimated for $95 \%$ confidence interval, there is no significant differences found of cognitive style of group 2 students on gender and grade variants ([p] 0,504>0,05 and [p] 0,557>0,05).

\section{DISCUSSION and RESULTS}

There are many studies showing which indicate the benefits of computer-based applications for children and adults in terms of providing motivation, developing skills and encouraging collaboration (Üstünel, 2012). A study related to computer-based learning environment showed that digital puzzle solving score was positively correlated with FI (Hong et al., 2012).

The results of this study indicate that in gifted education programs gifted students who were taken ICT-Based courses in Science and Art Center show more Field Independent (FI) property than other gifted students who were not taken ICT-Based courses. On the other hand, there is not any significant differences found on cognitive styles of gifted students in terms of gender and grade variants.

The results obtained through this study strongly confirm previous studies that Field Independent (FI) property showing students had higher scores or achievements than Field Dependent (FD) one (Xu, et al., 2011). Nicolaou \& Xistouri (2011) and Angeli (2013) found that field-independent learners outperformed field-dependent learners on problem solving performance. At the same time, 
Üstünel , H., Uçar, E., Civelek, T. \& Umut, İ. (2015). The relationships between field dependent/independent cognitive styles and information \& communication technologies based programs in gifted education. International Journal of Human Sciences, 12(2), 266-277. doi: 10.14687/ijhs.v12i2.3257

data collected in our investigation demonstrated that gifted students show more Field Independent (FI) property than not identified as gifted students show. Besides, there is no significant difference found on cognitive styles in terms of gender and grade variants for the sample of group 2.

It is certain that, cognitive styles have also effect on every student's performance as some other factors have impacts on. Teachers should be sensitive for these cognitive features of the gifted and should take into consideration when they present the new educational material to the gifted ones. For providing effective learning environments to gifted students, we have to identify their behaviours relevant to their cognitive styles. Interestingly a research's results reveal that there are not any significant demographic component differences (gender and grade level), but moral judgement level and emotional control were highest correlating variables in terms of problem solving of computer science course taking gifted students (Kim et al., 2013).

However, further research is needed to establish more relations between cognitive styles and other fields and disciplines such as science, math, biology, art etc. In addition, students of $9^{\text {th }}-12^{\text {th }}$ grades should be included to sample for future studies. For developing new teaching and learning assessment and evaluation techniques in special education for gifted students, it is needed to investigate student's intellectual property. In order to provide a special education to the gifted students who need it. A new educational atmosphere and new instructional materials are needed. We have to determine the factors that affect cognitive style positively. Thus, a more efficient way to reach a common sense which our society needs in related to gifted's special education methods.

\section{References}

Bahar, M. (2003). The Effect of Instructional Methods on the Performance of The Students Having Different Cognitive Styles. H.U. Journal of Education.24 : 26-32

Chan, K. W.,\& Elliott, R. G. (2004). Relational analysis of personal epistemology and conceptions about teaching and learning. Teaching and Teacher Education, 20, 817-831. DOI: 10.1016/j.tate.2004.09.002

Charoula, A. (2013). Examining the Effects of Field Dependence-Independence on Learners' Problem-Solving Performance and Interaction with a Computer Modelling Tool: Implications for the Design of Joint Cognitive Systems. Computers \& Education, v62 p221230 Mar 2013. 10 pp. DOI: 10.1016/j.compedu.2012.11.002

El-Banna, H. (1987). The development of a predictive theory of science education based upon information processing theory. Unpublished Doctoral Dissertation, University of Glasgow, Scotland.

Ford, N.(2000). Cognitive Styles and Virtual Environments.Journal of the American Society for Information Science. 51 (6):543-557. DOI: 10.1002/(SICI)1097-4571(2000)51:6<543::AIDASI6>3.0.CO;2-S

Hong, J.C., Ming, Y.H., Ker, P.T., Y,H.L., Li, C.L. (2012).Effects of CognitiveStyle on Digital Jigsaw Puzzle Performance: A GridWare Analysis. In Computers in Human Behavior. May 28(3): 920-928. DOI: 10.1016/j.chb.2011.12.012

Jonassen, D. H.,\& Grabowski, B. L. (1993). Handbook of Individual Differences, Learning, and Instruction, Hillsdale, NJ:Lawrence Erlbaum (p. 234).

Kim, H.S., Nam, S., Lee, W., Nam, K., Kwon, D. (2013).Effects of Moral Judgement, Emotional Control and Problem Solving on Information Ethics of Gifted Students in Computer 
Üstünel , H., Uçar, E., Civelek, T. \& Umut, İ. (2015). The relationships between field dependent/independent cognitive styles and information \& communication technologies based programs in gifted education. International Journal of Human Sciences, 12(2), 266-277. doi: 10.14687/ijhs.v12i2.3257

Science. Computer Software and Application Conference Workshops (COMPSACW), 2013 IEEE $37^{\text {th }}$ Annual. 633-638. DOI:10.1109/COMPSACW.2013.103

Kirk, S.A. \& Gallogher, J.J. (1989). Educating Exceptional Children. USA: Haughton Mifflin Company. p. 85

Messick, S. (1984). The nature of cognitive styles: Problems and promises in educational practice. Educational Psychologist, 19, 59-74

Nicolaou, A.A., Xistouri, Xenia. (2011). Field Dependence/Independence Cognitive Style and Problem Posing: An Investigation with Sixth Grade Students. Educational Psychology, v31 n5 p611-627 2011. 17 pp.DOI: 10.1080/01443410.2011.586126

Rittschof, K.A.(2010). Field dependence-independence as visio spatial and executive functioning in working memory: implications for instructional systems design and research. Education Tech Research Dev (2010) 58:99-114. DOI 10.1007/s11423-008-9093-6

Thomson, K., Watt, A., Liukkonen, J. (2014). Developmental And Cultural Aspects Of FieldDependence In 11 And 12 Year Oldestonian And Finnish Students. TRAMES, 2014, 18(68/63), 1, 89-101. DOI: 10.3176/tr.2014.1.06

Triantafillou, E., Pomportsis, A., Demetriadis, S. (2003). The design and the formative evaluation of an adaptive educational system based on cognitive styles. Computers \& Education 41 (2003) 87-103 DOI: 10.1016/S0360-1315(03)00031-9

Üstünel, H., Meral, M., Uçar, E., Umut, İ. (2012). The Factors Effecting Students’ PC Game Types Preferences. Procedia - Social and Behavioral Sciences, 47, 943-949. DOI: 10.1016/j.sbspro.2012.06.761

Witkin, H.A. \& Goodenough, D.R. (1981). Cognitive Styles: Essence and Origins Field Dependence and Field Independence. New York: New York University Press.

Witkin, H.A., Goodenough, D.R., Moore, C.A. \& Cox, P.W. (1977). Field dependent and field independent cognitive styles and their educational implications. Review of Educational Research, 47, 1-64. DOI: 10.2307/1169967

Xu, J.,Si, J., Zhang W.(2011).Distractors Interfere with Numerical Estimation in Chinese College Students as a Function of Fielddependent or Field-independent Cognitive Style1, 2.Psychological Reports, 2011, 108, 3, 825-842. DOI: 10.2466/04.22.PR0.108.3.825-842 